\title{
How Homeland Politics Affect In-group Differences in Identity Formation among Contemporary Chinese-Speaking Immigrants
}

\author{
Yuching J. Cheng \\ University at Albany, SUNY
}

January 2017

\begin{abstract}
The immigrant identity literature, which describes various routes to a range of identity claims, suffers from an assumption of mutually exclusive "categorical identities." In this study the author re-conceptualizes immigrants' identity formation as a historical causal process involving relational "identity categories." The sample consists of 56 highly achieving Taiwanese and Chinese immigrants with at least twenty-year lengths of stay. They respectively represent precedents and followers of contemporary Chinese-speaking migrants to the U.S. A major finding is that while Taiwanese immigrants tend to develop an exclusive identity formation process, the Chinese process entails inclusivity. I argue that this within-group difference has its roots in pre-migration conditions. Ethnic polarization in Taiwan has generated and sustained a political form of hyphenated-American identity, a process in which "Taiwanese," "Chinese" and "Asian" are perceived as mutually exclusive categories of identity. The lack of an equivalent premigration event for Chinese immigrants has resulted in the formation of a culturally hyphenated identity in which "Chinese" is interpreted as a symbolic ethnicity that complements Asian panethnicity. By addressing the enduring effects of homeland politics on immigrant identity, this study challenges existing ideas on associations among time/length of stay, culture/common language, and immigrant integration.
\end{abstract}




\section{INTRODUCTION}

Immigrant identity is one of immigration theory parameters. Ever since the originators of immigrant assimilation theory established a straight-line model predicting that immigrants and their offspring would eventually achieve upward social mobility and that fully assimilated individuals would desire mainstream white identities and intermarriages (Park 1928; Gordon 1964), racial and marital assimilation have been combined to measure the extent to which immigrants and their offspring have become structurally assimilated. While Straight-liners unify racial and marital assimilation by asserting that upward social mobility is the only possible assimilation outcome, segmented assimilationists are less strict about unification, preferring instead to underscore the positive effects of ethnicity of origin on integration and the possibility of downward assimilation among the children of immigrants (Portes and Zhou 1993; Zhou 1997; Portes and Rumbaut 2001).

Both straight-line and segmented theorists have faced challenges from scholars of transnationalism. According to many transnational migration researchers (e.g., Schiller, Basch and Blanc 1995; Levitt 2001; Pessar and Mahler 2003; Levitt and Jaworsky 2007), understanding immigrant integration requires not only a detailed examination of post-migration conditions (e.g., structural mobility, lengths of stay, cultural assimilation, marriage patterns), but also effort to trace immigrant roots and explore pre-migration conditions in the sending countries — that is, the factors that paved the way for integration. Among pre-migration conditions, homeland politics is a key factor illuminating how heterogeneity in immigrant identity is generated. Ocampo (2014) found that second generation Filipinos perceive themselves as Latinos more than Asian Americans because of the historical Spanish colonization of the Philippines, despite the 
downward mobility of many Latin groups. Accordingly, they are more comfortable dating Mexican Americans than Vietnamese Americans.

Even though segmented assimilation and transnationalism theories have served as a corrective to the strait-line assimilation model, the immigrant identity literature, which describes various routes to a range of identity claims, suffers from an assumption of mutually exclusive “categorical identities." It tends to fall into the trap of "groupism," in the word of Rogers Brubaker (2009), by assuming that race, ethnicity, and nationality are three separate essences. Further, the three theories of immigration suggest a positive relationship among time, culture, and identity/racial assimilation, but my research shows they can be negatively related.

Drawing data from Taiwanese and Chinese immigrants with at least twenty-year lengths of stay, respectively represent precedents and decedents of post-1965 Chinese-speaking migrants to the U.S., I find that while Taiwanese immigrants tend to develop an exclusive identity formation process, the Chinese process entails inclusivity. Most of the Taiwanese informants belong to what I call the "overseas February 28th generation." Their ethnic boundaries were shaped by the 1947 ethnic massacre of Taiwanese, an incident that divided the people of Taiwan into pro-China mainlanders and pro-independence islanders. Since the 1970s, an expanding nationalist movement focused on the roles of Japanese occupiers and Taiwan aborigines has focused on ethnic awareness among residents of the island, with considerable debate over the question of what constitutes "authentic Taiwanese." One effect of this movement is that Taiwanorigin immigrants in the U.S. have taken on identities that distinguish them from Chinese Americans. As a result, "Taiwanese American," "Chinese American," and sometimes "Asian American" have become mutually exclusive identity categories. For Taiwanese immigrants, this exclusive ethnicity category has led to the formation of a transnational political community that 
hinders their civic engagement in American politics beyond lobbying for the promotion of Taiwanese sovereignty.

In contrast, Chinese immigrants with at least one American-born adult child belong to what I call the "overseas June $4^{\text {th }}$ generation.” Directly or indirectly encouraged by the 1989 Tiananmen Square protests to leave China, their anti-communist ideology has led to the formation of American-first hyphenated identities. For these parents, being Chinese American means being culturally and symbolically Chinese, but politically American or Asian American. Intermarried parents are more likely to have cosmopolitan identities that reflect universal and/or American values. Applying this cultural essentialist approach to ethnic boundary formation enables them to not only fit in with pan-Chinese (huaren)from more developed countries, but also distinguishes them from the relatives they left behind, as well as from less-assimilated "fresh off the boat" Chinese.

By identifying the turning points of formation processes among Chinese-speaking immigrants, this study demonstrates the enduring effects of homeland politics on immigrant identity, recognizes the role of ethnic polarization events in deciding paths, and challenges existing ideas on associations among time/length of stay, culture/common language, and integration.

\section{FROM CATEGORICAL IDENTITIES TO IDENTITY CATEGORIES}

Immigrant identity research can be divided into three paradigms: race, ethnicity, and nationality. Scholars in each category have debated whether or not descendants of contemporary non-European immigrants (the so called "new second generation") become white, ethnic, or panethnic. While straight-line assimilationists lean toward the whitening of new secondgeneration members based on educational achievement and high intermarriage rates (Alba and 
Nee 1997; Kasinitz, Mollenkopf, Waters, and Holdaway 2008), segmented assimilationists assert that the children of non-European immigrants do not take on white identities despite their upward assimilation, mostly due to the mix of historical American practices of racial exclusion and people's racial self-perceptions (Portes and Rumbaut 2001; Zhou 2004; Kim 2007). Further, given changes in the content of whiteness and meanings of race (Kolchin 2002; Hughey 2010, 2014; Omi and Winant 1994), it is uncertain whether the taking on of white identity means the same thing across all of those who claim to do so.

The straight-line/segmented model debate is ongoing among ethnicity paradigm scholars. The straight-line camp has a negative view regarding ethnicity of origin, claiming that it slows down immigrant assimilation and that it becomes symbolic once later generations are fully Americanized (Park 1964; Gans 1979). Segmented model supporters believe in a more positive relationship between ethnicity of origin and upward assimilation, suggesting that it functions as a safety net, preventing the descendants of immigrants from falling into the underclass (Portes and Zhou 1993; Portes and Rumbaut 2001). According to this viewpoint, it is possible for second generation members who have achieved upward social mobility to claim hyphenated-American identity. Those who become involved in their ethnic communities and who feel proud of their immigrant parents and ethnic cultures are more likely to take on ethnic identities (Rumbaut 1996; Portes and Rumbaut 2001).

Within the nationality paradigm, both straight-line and segmented assimilationists acknowledge the effect of origin of nationality on the identification and integration of immigrants and their offspring. Once again, supporters of the former view nationality of origin as a negative factor and supporters of the latter view it as a positive one. Today's immigrantsending countries also appear to be more active in terms of institutionalizing the loyalty of their 
overseas nationals (Portes and Rumbaut 2001). Some scholars have observed that a small but significant number of second-generation members become long-distance nationalists who describe their parents' countries of origin as their homelands, and who emphasize their identities as being neither American nor hyphenated (Schiller and Fouron 2002, 2004). Thus, in recent years some scholars have started to explore what they call the "transborder membership" of nation-states by defining the citizenship policies of the sending country as a core component of nationalism (Brubaker 2010).

Researchers of all three paradigms_race, ethnicity, and nationality—face two challenges in the current decade: the growing number of mixed racial and ethnic populations (Bean and Lee 2009), and the growing literature on global and transnational migration (Kim 2006). According to the latest data, the multiracial population in America has reached 9 million, a $32 \%$ jump between 2000 and 2010 (U.S. Census Bureau 2012). The latest trend in immigrant identity research is applying a global conceptual framework to examining identity formations among children of contemporary immigrants in the U.S. (Kolchin 2002, Kim 2006). At issue in this line of research is to understand how America's imperialist, colonialist and militarist histories have shaped its relations with the sending countries of its immigrants (Kim 2006, 2007, 2008; Choy 2003; Roth 2009; Roth and Kim 2013).

However, it appears that researchers in these areas still tend to fall into the traps of dichotomy and groupism. Immigrant identity research has many examples of dichotomous operationalization and epistemology. Many scholars analyze immigrant identity in terms of internal versus external and racial versus ethnic versus national. Further, even though scholars have successfully transcended an essentialist approach so as to acknowledge immigrant identity as a historical and social construct, they still show an inclination to treat race, ethnicity and 
nationality as three separate elements, and to problematically assume that immigrant identity can be dissected along racial, ethnic, and national lines. They also tend to sidestep within-group differences in immigrant identity at the community level, and, in the words of Rogers Brubaker, To treat various categories of people as if they were internally homogeneous, externally bounded groups, even unitary collective actors with common purposes; and to take ethnic and racial groups and nations as basic constitutes of social life, chief protagonists of social conflicts, and fundamental units of social analysis. (2009: 28)

Quasi-essentialist assumptions regarding immigration culture are behind this groupist thinking tendency. However, as Barthe (1969) as noted, it is social boundary that defines an ethnic group, not culture.

I apply a "beyond-groupism" approach to examining identity formation among contemporary Chinese-speaking immigrants. As Brubaker (2009) asserts, this approach understands groupness as "a variable, not a constant; it cannot be presupposed. It varies not only across putative groups, but within them." He also argues that groupness underscores overlapping boundaries among race, ethnicity, and nationality, and therefore treats the three of them as "a single integrated family of forms of cultural understanding, social organization, and political contestation” (p. 21). Using Brubaker's immigrant identity research as a starting point, I will emphasize categorical variability within race, ethnicity and nationality rather than categorical distinctions among them - that is, I will address how racial-ethnic-national identity as a whole changes over time and across contexts. Using Brubaker's words, my research will be “comparative, global, cross-disciplinary, and multi-paradigmatic." I will attempt to understand identity categories cognitively and processually, and treat race, ethnicity, and nationality as "perspectives on the world," rather than "things in the world" (emphasis original). I will also 
treat them as "ways of making sense of the world ... templates for representation and organizing social knowledge, frames for articulating social comparisons and explanations, and filters that govern what is noticed or unnoticed" $(32,34)$.

\section{DATA, METHODS, AND CASE SELECTION}

\section{Taiwanese as Precedents of Chinese-speaking Immigrants}

According to 2010 U.S. Census data, Chinese is the second most-spoken foreign language at home, following Spanish (Pew Research Center 2014). But Chinese-speaking immigrants may originate from many different countries, the result of international Chinese emigration that began in the seventh century — twelve centuries prior to the first significant migration of Chinese to America. According to Yanagisako (1995), six or seven generations of ethnic Chinese have been born in the USA, with the first peak occurring between 1851 and 1875 , when $17 \%$ of all Chinese migrants choose the USA or Canada as their destinations (followed by Cuba [11\%] and Peru [9\%]). The large majority of these migrants were from Guangdong and Fujian provinces. The percentage dropped to 3\% following passage of the Chinese Exclusion Act in 1892 .

Taiwan has been a top ten sending country to the USA since the 1970s. Nevertheless, not all immigrants from Taiwan take on Taiwanese American identity. Many Taiwanese living in the United States view China and Taiwan as competing homelands, raising the question of whether they should be described as Chinese Americans or Taiwanese Americans - a question that divides many individuals within this group. Census data are conflicting: the number of people identifying themselves as Taiwanese Americans increased from 144,795 in 2000 (Lai 2003 ) to 215,441 in 2010 (Hoeffel et al., 2012), but the official number of foreign-born residents from Taiwan was 342,000 in 2000 - in other words, the $48 \%$ increase in individuals identifying 
themselves as Taiwanese American does not accurately reflect the number of actual immigrants from Taiwan over the last decade.

\section{Chinese Immigrants as Followers}

The number of Taiwanese immigrants has sharply declined as the number of Mainland Chinese immigrants has increased since the 1980s. Although Mainland-born Chinese dominated pre-1965 Chinese immigration, they were replaced by Taiwanese and Hong Kong-born Chinese when China prohibited or strictly limited the outmigration of its citizens from 1949 until well into the 1990s. A significant increase in the number of Taiwanese immigrants occurred after World War II, with Taiwanese students quickly becoming one of the largest immigrant groups attending American universities. A large percentage of these mostly middle-class Taiwanese became naturalized citizens after graduation. Hong Kong Chinese became the dominant incoming group for a short period in the 1990s due to the scheduled 1997 handover of the colony from the UK to China. Changes in China's migration policies and its growing economic power are two reasons for the dominance of Mainland Chinese immigrants since 1990. Contemporary Mainland Chinese immigrants tend to be students from middle- or upper-class families, and like their Taiwanese predecessors, they tend to stay after graduating (Zhou 2009).

\section{Controlling Post-migration conditions on a Community Level}

Data collection took place in the San Diego metropolitan area, one of the most popular destinations for Asian immigrants and their children. As of 2012, 13.2\% of all San Diego residents were of Asian origin, an increase from 7.4\% in 1990 and $10.5 \%$ in 2000 (Logan et al. 2012). More importantly, San Diego differs from other gateway cities in the number of secondgeneration residents, with $72 \%$ of its Asian American population being American-born (Census Bureau 2012). 
The sample was drawn from contacts I have made in the Taiwanese and Chinese American communities in San Diego as a volunteer for several organizations from January 2014 to June 2016. I then applied snowball sampling in the form of asking for referrals, making clear my interest in interviewing both second-generation members and their immigrant parents. In addition to attending events at ethnic centers, churches, and civic organizations, I have presented preliminary results of my research at two public talks. Leaders and members of these organizations have grown accustomed to my presence, and I have been approached many times with offers of help or contacts.

Interviewees were asked to talk about the racial and ethnic compositions of their nuclear and extended families, their expectations and preferences for their children's marriage partners, and how they get along with family members who come from different racial and ethnic backgrounds. All interviews (lasting from 30 minutes to 3 hours) were recorded and partially transcribed based on notes taken during each conversation. Interviewees decided whether to communicate in Mandarin, Taiwanese, or English.

In general, the Taiwanese and Chinese immigrants in my sample were similar in their socioeconomic status. The majority had an either M.A. or Ph.D. degree and lived in suburban areas, such as Carmel Valley, La Jolla, and UTC. They were different in lengths of stay and employment status. The Taiwanese generally had been living in the U.S. longer than the Chinese ones, for an average of 42.8 years. The Chinese tended to be middle-aged professionals.

EXPLAINING VARIATION IN IDENTITY FORMATION

Case One: Taiwanese American as an Exclusive Process

Ethnic Polarization in Taiwan 
The emergence of a Taiwanese American identity parallels the development of Taiwanese nationalism. Taiwan Island has had six colonial rulers since the seventeenth century, but as Hsiao (2012) notes, a sense of 'Taiwanese-ness' did not emerge until the 1970s. A Taiwan-centered historical perspective has grown over the past two decades, leading to a transition from 'China is part of the Republic of China' to 'Chinese culture is only one part of Taiwanese culture'. The first idea reflects the early twentieth-century creation of a Chinese republic that was dominated by a single political party, the Kuomingtang (KMT). That government fled to Taiwan when the Chinese Communist Party proclaimed victory in 1949, followed by decades of conflicting claims over which party could call itself the legitimate representative of all China. In Taiwan today, individuals whose families arrived with the KMT are still frequently referred to as 'mainlanders' (wai-sheng-ren), to distinguish them from 'islanders' (ben-sheng-ren, literarily 'the people of the province') whose Taiwan roots can be traced back many generations before 1949. In contrast to mainlanders who tend to view China as their homeland, islanders identify with Taiwan politically, and linguistically prefer Taiwanese/Holo dialects to Mandarin Chinese. A dwindling number of elderly Taiwanese consider Japanese their native language because they were raised by Japanese-speaking parents during the Japanese occupation from 1895 to 1945. In the wake of a new Taiwan-centered perspective, in which elements of Japanese and aboriginal cultures have been re-invented to challenge a Han-blood discourse that supports Chinese legitimacy, islanders whose ancestors at one time lived under Japanese control consider themselves 'authentic Taiwanese' as opposed to unauthentic mainlanders (Hsiau 2012). These identity categories_mainlander/wai-sheng-ren and islander/ben-sheng-ren — are still retained by Taiwanese immigrants who arrived in North America in the 1960s and 1970s. 


\section{Taiwanese American as a Political Identity}

[To be developed.]

\section{Case Two: Chinese American as an Inclusive process}

In all, 13 of the 20 Chinese immigrants I interviewed for this project brought up the subject of Tiananmen during our conversations, sharing opinions and insights based on their participation or observations. The percentage was higher among the 15 Chinese immigrant fathers I interviewed. Almost all of them described the incident as a major factor in their decision to emigrate. Three others purposefully avoided discussing the topic, claiming to have no opinions. I was surprised because the Tiananmen Square protest was not a topic that I planned to talk about during our interviews. I was therefore surprised to discover the association between the 1989 incident and identity formation among Chinese immigrants with at least one Americanborn adult child or twenty-year stays in the U.S. I have since come to refer to this sample as the "overseas June Fourth generation," and now believe that the historical origins of the event must be understood in order to fully understand what it means for members of that generation to be Chinese American.

\section{The Enduring Power of Tiananmen}

Calhoun (1989) has described Tiananmen Square as the place where "the true believers came for inspiration, for a glimpse of Mao, for the most Durkheimian of collective representations of social membership" (56). The 1989 Tiananmen protest exerted effects on both internal Chinese politics and international relationships between China and the rest of the world. They are better viewed as the culmination of a student movement that had started three months earlier. Zhao (2000:159) provides this brief chronology: 
Beijing students started the movement on April 15, 1989, upon Hu Yaobang's sudden death. The movement achieved some success by early May. However, unlike the two earlier student movements, the 1989 BSM [Beijing Student Movement] was not able to sustain its success. While the government was pushed to make limited concessions, a few students started a hunger strike at Tiananmen Square on May 13 to demand more radical changes. The action drew hundreds of thousands of sympathizers once the condition of the hunger strikers deteriorated. The hunger strike was a big success in mass mobilization. However, it interrupted the Sino-Soviet summit and antagonized most of China's top state leaders. Thus, the government announced martial law. Yet, martial law could not be carried out immediately. On the night of May 19, in a popular belief that the soldiers were going to harm the students in Tiananmen Square, Beijing residents went out by the hundreds of thousands and stopped the army. The troops had to withdraw, and the student occupation of Tiananmen Square was preserved. Then, on June 3, the army entered Beijing once again. They met with violent resistance. Yet with much more resolute orders from the government, the troops pushed their way through the square, leaving behind several hundred dead and thousands more wounded. The movement was suppressed, but people did not forget. Much of Chinese politics since then has centered on the ghost of the movement and its aftermath. The impact of this movement on China's politics has yet to be fully realized.

"The ghost of the movement" still resides within the minds of students who participated, even those who moved overseas to study and who mostly made their migration permanent. The primary mechanism underlying the June Fourth events is debatable. Calhoun (1996) has described the role that culture played in generating group solidarity (as well as in the ultimate 
failure of the movement), and Zhao (1998) has shed some light on the material foundation and the effects of campus ecology on student mobilization. According to Zhao (1998), campus ecology was operationalized as a meso-level condition involving the spatial layout of the Beijing university campus, dormitory-based networks, and the distribution of the student population. Zhao (1998) initially challenged the idea of a cultural "metanarrative" for the movement, but later (2000) attempted to understand how moral perceptions of state legitimation had roots in the Cultural Revolution, and how they resulted in the overall traditional outlook of the movement.

Although scholars are in disagreement about the underlying mechanisms of the movement, they agree that the roles and identities of the student participants are key to understanding its trajectory. Calhoun (1996:23) suggests that to better capture the ups and downs of the movement, the students should be analyzed as "uncompromised intellectuals" rather than simply "actors," and that they were "moved by a sense of national identity and of profound cultural crisis." One consequence was their failure to make "common cause" with non-educated Chinese citizens (1996: 23).

\section{Chinese Immigrants as an 'Overseas June Fourth Generation'}

Zhao (1996) refers to these students as an "aggrieved population" cohort in China, a group that was "ready to be recruited when the 1989 BSM started" (160). This cohort is marked by three characteristics. First, it is a small population mainly consisting of elite students enrolled in the best Chinese universities in the 1980s. Second, its members had a desire to study abroad long before 1989, since they saw foreign study as a "safety-valve" providing "hope and a way of escape" (Zhao 1996:152). According to Zhao, “going to America” was a fever among Chinese college students throughout the 1980s, even though the goal was difficult to achieve due to reduced Chinese government funding and increasingly harsh requirements, including political 
examinations, 2-5 years of working prerequisites, and program limitations. In a survey conducted in $1990,80.2 \%$ of the student respondents felt that China's foreign study policy was “unreasonable" or "extremely unreasonable" (Rosen 1991:179; cited in Zhao 1996:159).

I found evidence of this "U.S. fever" during my interviews. Sean told me he was just "following the trend":

It was a fashion. Everyone came to the U.S. It was easier to come here. The reason I chose to study in the U.S. was in relation to my situation at that time. The mainland was poorer at that time. Although I was working - I was already a graduate student — the monthly salary was low. I earned six RMB as a graduate student at that time. Generally speaking, graduate students were poor unless what you learned was in the government's focus area. In short, I was poor, so I wanted to go abroad.

Third, this cohort was heterogeneous. The composition of student participants changed over the course of the movement, with more females and non-elite undergraduates getting involved (Calhoun 1989). In addition to between-group heterogeneity, within-group differences also presented challenges to the movement.

\section{Anti-Communist Ideology}

Most importantly, the 1989 student protest in China fueled an anti-Communist ideology in this cohort consisting of elite students attending Chinese universities in the 1980s and 1990s. This cohort was influenced by and increased a sense of student nationalism that continues to shape China. According to Zhao (2002), nationalism is better defined as "about a certain people's perception than about the objective reality as seen by outsiders" (890).

Even though this anti-Communist ideology weakened over time, it was never replaced by anti-U.S. nationalism. In his examination of the U.S. bombing of the Chinese embassy in 
Belgrade in 1999, Zhao (2002) concludes that anti-U.S. nationalism was not a reality among elite college students in China,

[who] had very ambiguous feelings towards the United States: they disliked some of the United States' foreign policies, but they thought very highly of American democracy, greatly admired America's achievements, and wanted either to study in American universities or to work in American companies. A great admiration of the United States' political system plus other personal interests had prevented the development of antiAmerican feelings among Chinese students. (903)

Those students who were successful in getting into American universities brought with them emotional memories of the 1989 Incident, with some purposefully distancing themselves from the events. Greg Chen, 52, moved from Nanjing province to Singapore, and then to the U.S. to earn a Ph.D. in electronic engineering in 1991. Greg married one of his college classmates before moving to the U.S. He is a father of two (a twenty-year-old son and a nineteen-year-old daughter) and a senior manager for Qualcomm, a large wireless technology company headquartered in San Diego. Greg's immigration history fits with the post-1989 cohort's, but he consciously refrained from discussing his Tiananmen-related experiences during our interview.

However, the majority of interviewees willingly discussed Tiananmen (often without my prompting) when describing their reasons to leave China and their perceptions of what it means to be Chinese American. Peter Rong, a 50-year-old real estate agent, did not hesitate to describe his experience:

When I went to school as a young adult, you wanted to have something better for this society. I was the chair of the student union ... in the depths of my heart I wanted to do something influential to help people ... There were already student protests when I was in 
Anhui in 1987. That's prior to 1989. If you read wiki, it started already in 1987. I was part of the movement in 1987. I met many southern students from my school. We became the central part of the protests because we wanted a better government, better democracy. It was always my dream back to that teenage time. So in 1989, when the government started to crack down the movement, I felt desperately helpless, and I knew there was nothing I could do to change that country. I told myself, "This is not the place where I want to stay, and these people don't need my help. They don't need to be awoken. Screw you guys, I'm out of here. I'm pursuing my personal achievements."

For other informants, Tiananmen Square was not merely a "push factor," but a turning point in their life trajectories, one that strongly altered their chances of success. Sean described himself as a direct victim:

The June $4^{\text {th }}$ Incident had a direct effect on me. In fact, I had already received admission in 1990 - I graduated in 1989 and I applied for schools in the United States once I graduated ... We had to be awarded a full scholarship to study abroad. It was Yale that gave an admission. I was admitted by many schools; Yale was one of them. But then came June $4^{\text {th }}$. The Chinese government changed its study abroad policy, and made it impossible to get a passport. I couldn't [go abroad], not because of the visa but because of the passport ... [The new rules] said that your application for a passport would not be accepted unless you had a relative in the U.S.- or outside of the country, not necessarily in the U.S. Thus, I was a direct victim of June $4^{\text {th }}$. Many people were out of there once they graduated from college. Many of my classmates made it that way. It had little effect on them. I was not in a rush when in college. So when many people already started to apply in their third or fourth year, I didn't do it. It is said that there are many factors 
affecting one's life. Some things are out of your control. Diligence decides one's success. But many times it also depends on many external factors. You happen to be in the right place at the right time, and you succeed.

Some informants did not physically participate in the Tiananmen protests, but still view themselves as participants and insightful observers. Dan, 46, a Nanjing resident who came to the U.S. in 1993, became animated when recalling the protest:

I experienced the June Fourth Incident because I went to college in 1988. The June Fourth Incident happened in 1989. It might be the only time that China was so close to the West. It totally had a chance, but unbelievably it was ... The government put it out just for its own interests, for a small group of officials to keep riding on folks' backs. This was very, very selfish. The Communist Party, the people in high places who actually don't follow communism to do things. Communism was used to fool the people below. How can you sacrifice yourself for it? Everything they did was totally selfish. They didn’t consider ordinary people, they didn’t consider universal humanism. It was totally a policy of deceiving people. The country has had many chances, but they use the so-called communism to ... I hope China can soon give up all of these things, like living in lies.

\section{'Chinese American' as Cultural Identity}

In many cases, anti-communist ideology has facilitated the formation of an "Americanfirst" hyphenated identity among members of the overseas June Fourth generation. The majority of my highly achieving Chinese informants have taken on Chinese American identities, with their Chinese backgrounds interpreted as examples of "symbolic ethnicity." Greg, the senior manager at QUALCOMM, is an example. Although he has spent enough time in his adopted country to become assimilated, he still strongly identifies with his ancestral ethnicity: "Always 
Chinese, it's about blood and culture. Being Chinese means keeping Chinese traditions and culture. Food, cultural advantages, values, family sacrifice, and education, [these are] 'Chinese benefits." Similarly, Sean strongly associates Chinese traditions with family values. "I feel one thing different [between China and the U.S.] is that in China they still value family relations, like respecting the old and cherishing the young. These traditions were the education I received as a child. At least it was the situation in old times, but maybe it has changed now." The idea that Chinese culture emphasizes family cohesion was also mentioned by Peter, the real estate agent: "Chinese culture has a good thing and a bad thing. The thing I like is its best values, common values. I think the most important Chinese value is family. The second most important value is education."

Some informants expressed neutral attitudes regarding the meaning of being Chinese, and kept cultural and political implications at a distance. One example is Yvonne, 55, a senior software programmer for the TurboTax Company and a single mother of two children, one eighteen and one sixteen. Sitting in the company's spacious food court, Yvonne radiated confidence and independence. She worked in Singapore for several years before being recruited by an international agency and moving to the U.S. in 1993. Yvonne's immigration path is different from those followed by the majority of her cohort, and that difference is reflected in her interpretation of being Chinese. "I am of course Chinese American," she told me, but she deemphasized the Chinese effect- "It has no meaning for me. That's a fact. It just means that I was born and trained and received primary education in China. It's just a fact." However, the more we talked, the more she exposed her symbolic Chinese ethnicity, especially in terms of traditional values tied to education and morality: 
In fact, I feel I am more American in terms of lifestyle. I live like an American. But deep inside, I am Chinese. I am more culturally Chinese due to the traditional education I received. My ethics, my morals, are more like Chinese. For example, when working, if I take a job assignment or a project, I make commitment to it. I work hard on it. I think this spirit comes from my original education.

For some of my informants, defining their Chinese connection in a culturally symbolic way stressed the American component of their hyphenated identities. Dan's strong rejection of communist ideology clearly impacts the way he interprets the meaning of being Chinese American.

"I feel I should be Chinese American. I personally identify with American ideals. Taking on this identity means, of course, I am Chinese in terms of blood lineage, but coming from the Mainland and living there for twenty-three years, I do not feel many of the good traditions kept there. I came here and I feel cultural differences. Its [U.S.] culture and values are definitely better than those of the Mainland."

"May I conclude that you see yourself more American than Chinese?"

"Yes, you can say that. I appreciate American culture more."

\section{Hyphenated Identity as a Group Difference Perception}

Prioritizing American over Chinese values reveals an individual's perceptions of between-group differences. As Dan told me,

In general, I feel I am happier in the U.S. than on the mainland. There are fewer suspicions among people. Much more sincerity here. Generally speaking, this society is more inclusive. Of course, sometimes I feel discriminated against. But in general, everyone is fairer. 
Choosing what to prioritize in a hyphenated American identity reveals not only individual perceptions of group differences, but also of attitudes toward China and the America. Dan told me,

They differ a lot. The Chinese government has long refused to apologize for [the] Cultural Revolution, a terrible, horrible thing that did harm to so many people. A society filled with lies. In the U.S., you feel its systems, like the separation of the three powers, whatever, it has established a great system that allows people have opportunities to speak the truth ... When I was a kid, I saw the official news broadcast in China and believed everything the government said. But then I realized things were totally different, it went too far from what the reality is, too many lies. The knowledge of historical events, the knowledge of historical people, the reports of social reality, all are very fake! Another example of how interpretations of what it means to be Chinese American manifests in Chinese immigrants' moral perceptions of group differences between China and the U.S. came from Peter, the real estate agent, who felt motivated to study abroad because of Tiananmen. He justified his taking on a strong American-first identity by comparing the greed of China and the generosity of the U.S.:

I consider myself an American with Chinese background, because this is my country. You might say that China raised you for twenty-five years. I say it all depends. When I graduated from China, they [at first] wouldn't let me leave, and ordered me to pay what they called “training expenses” (培養費) ... If you hadn’t yet worked for five years, full time, you had to pay ten thousand dollars for one year. I was earning one hundred and twenty dollars a month at that time. That's a lot of money. I had to pay it or I couldn't get my passport. Of course today the culture has changed. People make more and think that 
it's not a big deal; everybody can make that ... When I came here, and the school provided the best benefits to me as a full-time student, a scholarship and tuition waiver. So that part shows how generous this country is. And guess what? The first place I went to was Oklahoma, but at that time I was so naïve. I didn't really recognize people's prejudices and biases. I kind of enjoyed that place, and I still feel they treated me nicely, you know. I didn't feel I was being treated by a racist. As a matter of fact, the dean of my department was an Asian. He was a Chinese, a great man. I spent a lot of time with American friends and tried to learn the sides here. Sometimes I also gave them perspectives of China, especially of the Tibet situation. A lot of people started to understand it. Tibet is one of the biggest issues and a lot of Americans don't know what that is.

The comments made by Dan and Peter on what it means to be Chinese American reveals how cultural and biological essentialisms work together to shape ethnic boundaries that distinguish individuals from others. Dan initially recognized his Chinese ancestry as being based on biological essentialism — “blood lineage." He then described his perceptions of differences between Americans and Chinese in terms of cultural traditions. From his comments I concluded that cultural essentialism played a more important role than biology in his drawing of ethnic boundaries, since his perceptions of racial/ethnic group differences are based on variations in cultural values ("values are definitely better than on the Mainland") and "good traditions." The result is an overlapping of ethnic, national, and moral boundaries among Chinese immigrants. Identity, Morality and Essentialism 
The overlapping of ethnic and national boundaries allows Chinese immigrants to occupy a self-perceived superior status regarding morality. This is exemplified by Yvonne's description of moral differences between Chinese and Americans:

I'm not saying that whites are immoral. But when doing things, if they are difficult, I will keep digging into that. I will not give up. But they, many of them, will request for more discussion, more interaction with other people. But Chinese will find maybe other ways around [roadblocks] sometimes. We will be, at least for me, more independent and try to dig into things overnight. This is not totally about Chinese [versus] American. But anyway, it is at least true for those who I've met. Generally speaking, Chinese are doing things that way.

Compare her observations with Dan's perceptions of the way things are done in the U.S. and China, with the former associated with good culture, truth, and public interest, and the latter with poor culture, lies, and utilitarianism:

The twenty-year education I received there was very narrow. Money was put above everything. I felt very ridiculous, many lies. After coming to the U.S., I feel everyone is more honest, more down-to-earth. In terms of values, everyone [here] is doing things for the public interest, and doing these good things from the bottom of their hearts, not just for ... In the mainland, everyone does things in a utilitarian manner ... [It] makes me more identified with values in the U.S. in terms of ideals and thinking. It is because of the process I grew up with. Although I speak Chinese and was raised to be pan-Chinese, I did not receive good culture [al training] for the more than twenty years I stayed in China. I feel the culture in the U.S. is better. I personally identify with it, and I also hope to absorb U.S. culture. 
Dan's use of morality to distinguish himself from other Chinese was similar to Peter's, the real estate agent who decided to study abroad because of his perceptions of an "unawakable China" in 1989. Upon his arrival at our interview location, it seemed as though he couldn't wait to say that he agreed to meet with me "because I feel I have to bring you another opinion, another version of Chinese." An international student at 25 who would soon turn 50, Peter identified himself as "half Chinese and half American," but he insisted on using English throughout our interview. During our interaction it seemed clear that he was one of many Chinese immigrants who have adopted an "American-first" hyphenated identity augmented by a symbolic ethnic Chinese identity:

Coming to a dinner table, I am more Chinese. I am eating with chopsticks, and that's the Chinese part. But in terms of other values such as hygiene matters, I think I am more American. American culture is healthier. For example, in Chinese culture we kind of dig through everything with chopsticks. We don't see that very often in American culture. That is unsanitary. You don't see that at a dinner table in the U.S., but Chinese all dig in the same place. That's why sometimes when I go to a party I feel distanced from that culture. It is not about which culture is better, it's about hygiene.

Whereas Dan associated his Chinese ancestry with biological essentialism, Peter associated his with cultural essentialism, although he went out of his way to avoid promoting one as better than the other. Peter drew an ethnic boundary along moral lines by addressing both cultural differences and a sense of modernity in the form of hygiene and health practices-a binary perception of between-group differences based on cultural essentialism. Doing so allowed him to draw ethnic boundaries along moral lines that overlapped with cultural and national ones. Taiwanese as Authentic 'Us' 
Defining "Chinese American" as a cultural identity allowed my Chinese informants to extend their ethnic boundaries to Taiwanese/Taiwanese Americans, and to perceive them as "us." Yvonne told me, “I have Taiwan-origin friends. I'm not sure if they call themselves Taiwanese. I think they are also Chinese American. In general, if you speak Chinese, you are part of that." In contrast, Sean acknowledged subtle differences between the two versions of spoken Chinese that are considered "standard" on the Mainland and in Taiwan. He told me, "I knew you were Taiwanese the second you spoke. Your accent and your tone are Taiwanese. For example, 'Mr. He' [He Xiansheng] — mainlanders don’t say it that way.” Linguistic differences aside, Sean still perceives Taiwanese as part of the category labeled "Chinese"-actually, he perceives some parts of Taiwanese culture as being "more Chinese" than what he had grown up with:

I heard that in Taiwan the culture, customs, values, and so on are probably more traditional than those in China. Those in China have already been lost because of the Cultural Revolution. Relatively speaking, Taiwan is more traditional. Those traditionslike respecting the old, cherishing the young, and loving your family—are probably deeper in Taiwan.

This perception of Taiwan as a keeper of "authentic" Chinese culture was also expressed by Dan: I have been in the U.S. for over twenty years, and in general, people from Taiwan do have good qualities in culture. And they are more believable. I am very glad that China still has Taiwan, with the same culture as China, even though they are now two separate governments. But Chinese culture was truly preserved in Taiwan. People from Taiwan and the mainland must be different in their living habits. The whole habits in family are different. 
In addition to culture and morality, some Chinese immigrants I spoke with made a distinction between Taiwanese and Chinese in terms of civility. Peter praised Taiwanese for their sense of human rights and democratic principles:

I have a lot of friends from Taiwan. Some people's backgrounds are strongly related to China, some are not. I learned that perspective from both sides. That is an extraordinary opportunity for me to understand Taiwan. And I think Taiwanese, in a lot of ways, have evolved in their own way. It's different from what we have in China. Let's put it this way, Taiwan produced Ang Lee, a world-famous director, right? They produced Jason Wu, a fashion designer, right? He designed the dinner gown for Michelle [Obama] ... He was brought here because of his very girly side. Wu is probably homosexual, a gay. But his parents saw it as a gift. They had no problem about that. But I would say about $99 \%$ of Chinese in China would not accept that. They would try to correct that. His mom knew that Taiwan at that time would not accept him either. But his mom has good values, like the mother of Mencius, who “moved three times” (孟母三遷)

Most people from China, we are not giving, we are taking. We are taking more, we ask for more and more and more. We are more self-centered. That's what I see; of course you know that maybe a lot of people disagree with me. We have a hard time recruiting people and getting people to donate money, to get people involved.

My data indicate that the perception of Taiwanese by Chinese as members of an authentic "us" group has not been affected by the declining economic power of Taiwan compared to China. According to Dan,

Twenty-three years ago, that's when I just came to the U.S.; Taiwanese were certainly richer than mainlanders. Now it's different. But people from the mainland still lack 
cultural upbringing ... When I am with mainlanders, including my old classmates, I feel estranged from them. They are not trustworthy. Hanging out superficially is OK, but if you really have something ... I've seen classmates do things to each other that were insane. They made up some excuses and harmed others for their own interests. Even though they tell you that "we are both laoxiang" [老鄉, roughly translated as "mates" or "comrades"] on the surface, they stab you in the back. I feel Taiwanese are more decent. Symbolically interpreting the concept of "Chinese" also supports the application of culture and biology to categorizing all Chinese-origin people as "pan-Chinese." Sean gave me this definition:

Pan-Chinese refers to those who were once connected to the mainland. They may have been born there, or grew up there, and then migrated away. Or they may be people whose ancestors lived there, they are also pan-Chinese ... Taiwanese and Hong Kongese are also pan-Chinese. Even those born in Vietnam are pan-Chinese. We call them Vietnamese overseas Chinese [Yuannan huaqiao, 越南華僑].

Peter also expressed a sense of heterogeneity when discussing the idea of "Chinese," and described pan-Chinese as anyone having a "Chinese background":

The situation in Hong Kong is probably easier because most people recognize that they are Chinese. For people from Singapore, they recognize that they are Chinese. For people from Taiwan, there are a lot of perceptions. Many people don't recognize themselves as Chinese. I cannot enforce my definition on them. I will say, you know, my definition will be Chinese and Chinese-background. Chinese is a word that's difficult to define. PanChinese is probably easier to define for those who have a Chinese background, and “Chinese people” [Zhongguoren, 中國人] are easier to define—-the people of mainland 
China. People from Singapore, Hong Kong, and Malaysia are more like pan-Chinese, like Singapore pan-Chinese or Taiwan pan-Chinese. Maybe that will be easier for clarifying the confusion. It's unfortunate we haven't invented a better word in English yet. You know, the majority in this country, they just consider people from China as Chinese. That's what it is, and that's what causes people from Taiwan to choose their words very carefully and differently.

\section{'Asian American' as a Political Identity}

Inclusive Chinese ethnicity not only helps Chinese immigrants to blend in with Chinese overseas, it also promotes an Asian American identity. For my informants, the terms "Chinese American" and "Asian American" are not mutually exclusive. Some see their co-existence as based on a commonly shared division between the two identities. Dan told me that he felt it was OK to be called Asian American "as long as it is American":

To me, each Asian group is different in terms of its native language. Each has its own traditions, too. I respect each of them and what they bring in, like the Lao community, Vietnamese community, and the Indian community, as long as everyone identifies with American. I think that is the most important thing-different, but American.

Yvonne was one of several informants who used Asian American as an umbrella category covering Chinese. She told me that she felt completely comfortable with being called "Asian American":

You see, there are many forms without the mark of Chinese American on it ... Asian American may include non-Chinese Asians, so being called Chinese American may be more representative. I think it depends. For example, in my company, it's a very large one. There are many Americans, aka whites, and non-immigrants. You say to them that 
you are Asian; "Chinese" is easier to understand. If I say I am Asian, they may not think I am Chinese. They may think I am Vietnamese. I have that kind of feeling.

Her opinion was echoed by Peter:

When you say "Asian American," it is a giant pool. Even the people from the Philippines, people from Singapore, people from Malaysia, people from Indonesia, Japanese as well as Koreans, even Chinese ourselves, we have people from Singapore, Hong Kong, Malaysia, Indonesia, Taiwan, even though Taiwanese do recognize themselves as Chinese. It's a huge difference. I see it [Asian American] as a category about how you define yourself. Asian American is a broader category, and when you claim it, it includes Japanese American, Chinese American, whatever you want to call them. I think it's just a category, just a name.

A number of Chinese immigrants I spoke with defined "Asian American" as a political identity that complements "Chinese American" as a cultural identity. This viewpoint was best expressed by Sean:

"Chinese American" and "Asian American" are hard to tell apart. I know many Asians, but most of my friends are definitely Chinese. There are many differences, but being an Asian American is mostly based on political concerns ... but culturally speaking, I go for Chinese.

... I am a naturalized U.S. citizen, so I am kind of both. Of course there are still some Chinese traditions, this is part of being Chinese. But politically speaking, Chinese is too narrow to be a race. Compared to other Asian groups, being Chinese is too small in number to fight for political rights. So many times we are put side-by-side with Asians .... 
When filling a census I choose Chinese, but "Asian American" when in need of help from Asians.

\section{CONCLUSIONS AND IMPLICATIONS}

[To be developed.] 